David Sánchez Fabra ${ }^{1,2}$

Elena Abad Villamor ${ }^{3}$

Susana Clemos Matamoros

Juan Valle Puey'

María Jesús Igúzquiza

Pellejero ${ }^{1}$

Ángel Luis Garcia Forcada ${ }^{1}$

\section{Woman with necrotising granulomatous lymphadenitis: the key was in anamnesis and physical examination}

\begin{abstract}
'Área de Medicina Interna del Hospital Reina Sofía de Tudela, Navarra, Spain.
${ }^{2}$ Grupo de Investigación Clínica en Enfermedades Infecciosas (G069) del Instituto de Investigación Sanitaria de Aragón. Spain.

${ }^{3}$ Medicina Familiar y Comunitaria del Hospital Reina Sofía de Tudela, Navarra, Spain.
\end{abstract}

Article history

Received: 25 September 2021; Revision Requested: 21 October 2021; Revision Received: 6 November 2021; Accepted: 26 November 2021; Published: 2 February 2022

\section{CASE PRESENTATION}

A 48-year-old woman was referred to the internal medicine outpatient department (OPD) due to an enlarged lymph node in her left axilla. Before the consultation, a core needle biopsy (CNB) had been performed with a pathological diagnosis of necrotizing granulomatous lymphangitis (NGL). Polymerase chain reaction (PCR) of the sample for $M$. tuberculosis complex was negative. The pathologist recommended complete excision of the lymph node to obtain more tissue for analysis. The surgeon referred the patient to internal medicine OPD before performing the procedure.

Anamnesis and examination were conducted. The patient lived in a rural area in Spain. She worked in a kindergarten and had no toxic habits. Her past medical history was unremarkable. No allergies. Regarding her family history, a grandmother had had breast cancer and a cousin had Hodgkin's lymphoma. She takes care of two dogs and six cats at home and volunteered at an animal shelter. Her pets had had ticks but she did not remember having ever had any tick bite. She had not made any trips abroad. She was on tramadol, acetaminophen, celecoxib, and omeprazole.

Current illness begins five months before the consultation, when a "lump" was noticed in the left axilla. The size of the mass has remained constant throughout this time. She did not have fever, constitutional syndrome, chills, headache, or arthromyalgia.

Physical examination: Body mass index of 40 , blood pressure $129 / 94 \mathrm{mmHg}$, temperature $36.5^{\circ} \mathrm{C}$ and heart rate 70 beats per minute. She was in good condition. No jugular ingurgitation. Cardiopulmonary auscultation and abdomen exploration were normal. A small and painless mass could be palpated

Correspondence

David Sánchez Fabra.

Área de Medicina Interna del Hospital Reina Sofia de Tudela, Navarra, Spain.

E-mail: davidsanchezfabra@gmail.com at the left axilla, apparently not attached to deep layers. No other masses or enlarged lymph nodes were palpable at any other location. There were multiple cat scratches on the upper limbs (Figure 1). Examination of lower extremities was unremarkable.

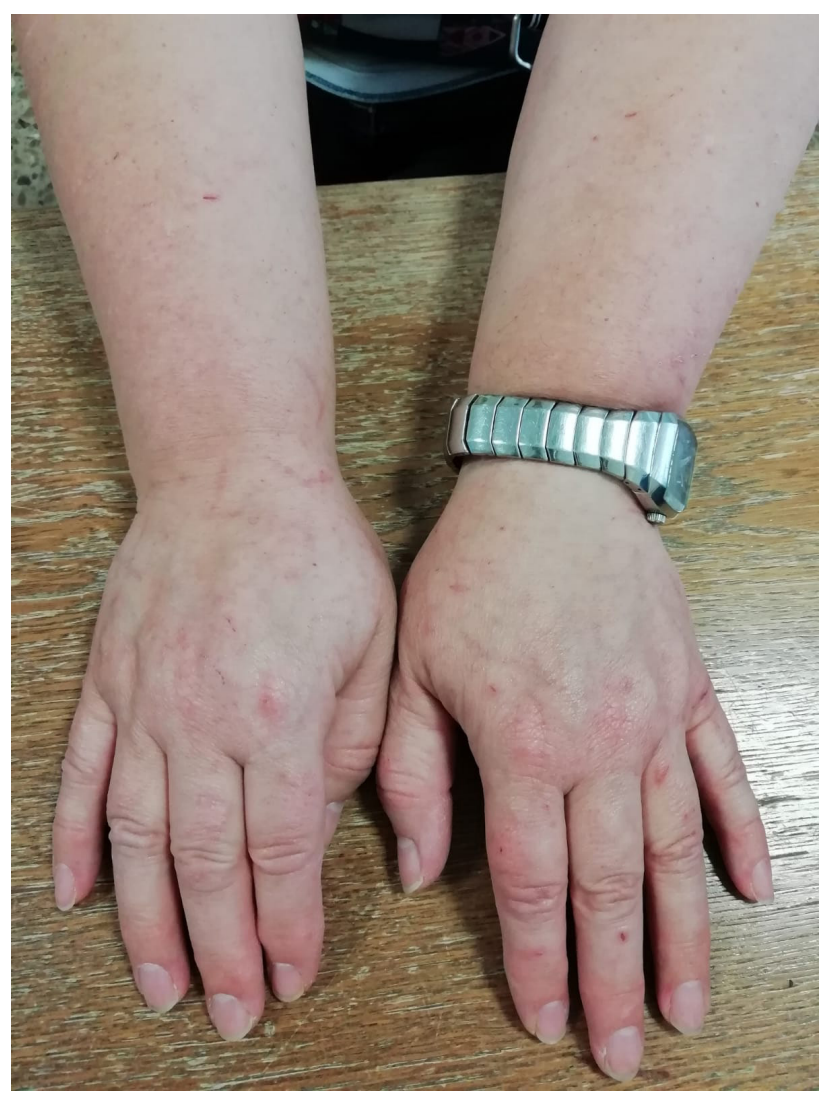

Figure $1 \quad$ Multiple cat scratches on the upper limbs 


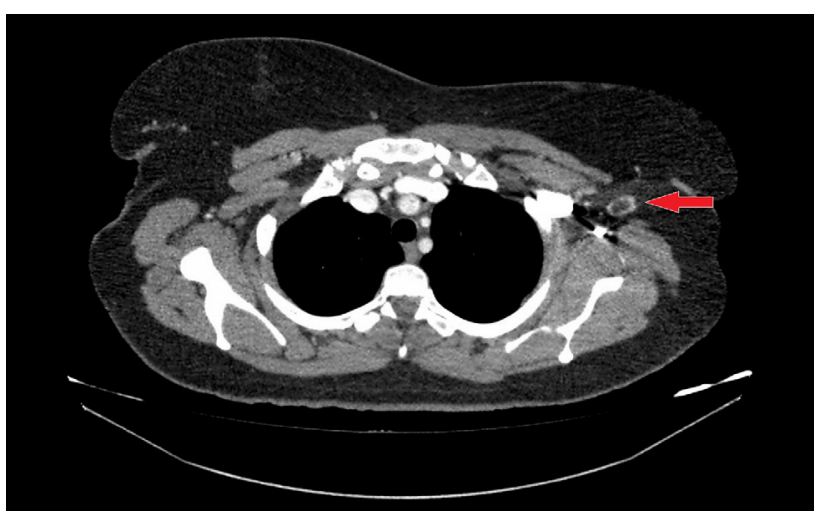

\begin{tabular}{l|l} 
Figure 2 & The CT scan was normal except for the
\end{tabular} already known adenopathy in axilla.

In addition to the above-mentioned pathology data, the patient had a normal chest X-ray and mammography.

\section{DIFFERENTIAL DIAGNOSIS}

In summary, we have a patient without any type of general or infectious symptoms, with a family history of cancer and a single lymphadenopathy located in the left axilla with a pathological diagnosis that shows NGL. Regarding these data, the working diagnosis in based in two aetiologies of her condition: infectious and non-infectious.

Among the non-infectious causes it can be found sarcoidosis, a disease that can be paucisymptomatic and, although in most cases there are enlarged hiliar lymph nodes, they can also occur in extrapulmonary territories such as the axilla. Others that should be taken into account would be haematological malignancies (Hodgkin and Non-Hodgkin lymphoma), berylliosis and tumor metastases, which rarely cause necrosis [1]. It should be noted that there was a necrotizing component in the adenopathy, which would make it necessary to include Kikuchi's disease, in which adenopathies are the most frequent sign although they are usually cervical and more typical in children and young people [2], and systemic lupus erythematosus [3], but there were no other signs or symptoms leading to this diagnosis.

As for infectious causes, the differential diagnosis is broader. We could further divide infectious entities in suppurative and non-suppurative causes. Among the former are tularemia, cat scratch disease, Yersinia pestis and fungal infections. Regarding the non-suppurative ones, the possibility of tuberculosis, non-tuberculous mycobacteria, toxoplasmosis, leprosy, syphilis, brucellosis and some types of fungi should be considered. Some of these diseases are highly unlikely, due to the almost complete lack of symptoms and location of the lymph node. For instance, $Y$. pestis infection would affect mesenteric lymph nodes, within a general picture of severe disease; in Epstein-Barr Virus infection (EBV), enlarged lymph nodes are usually bilateral, predominantly cervical, and do not present granulomas [1].

To reach the diagnosis, the wounds on the arms and hands were crucial, what it would entail the loss of the integrity of the skin barrier. This finding reinforces the possibility of the infectious cause, and it may be due bacteria of the skin flora (bacterial adenitis due to $S$. aureus) or bacteria related to an occupational context. Let us remember that these wounds had been inflicted by cats, so the cat scratch disease, caused by $B$. henselae should be evaluated first, without forgetting other zoonoses such as those transmitted by fleas or ticks (Lyme disease, rickettsiosis, anaplasmosis, babesiosis or tularemia) [4].

\section{PERFORMED TESTS AND CLINICAL EVOLUTION}

In the OPD, it was requested a thoracoabdominal Computerized Tomography (CT) to search for other regions lymphadenopathy and a complete analysis with biochemistry, hemogram, peripheral blood morphology, proteinogram, immunoglobulins, inflammatory reactants, autoimmunity study (rheumatoid factor, Anti-nuclear Antibodies and Extractable Nuclear Antibody), Interferon-gamma release assays (IGRAs; M. tuberculosis) and serologies of $T$. pallidum, EBV, T. gondii, Cytomegalovirus, Hepatitis B and C Virus, Human Immunodeficiency Virus, C. burnetii, B. henselae and Rickettsia spp. The CT scan (Image 2) was normal except for the already known adenopathy in axilla. All blood studies were normal, including inflammatory reactants, except for serologies, being Bartone/la spp. pathological, with results of: $B$. Henselae lgG, 1/4096 (pathological> 1/256); IgM, 1/80 (indicative of recent infection> 1/20). B. quintana $\lg G 1 / 256, \lg M 1 / 20$ (indicative of recent infection $>1 / 20$ ), by indirect immunofluorescence. With a diagnosis of cat scratch disease, outpatient treatment was started with azithromycin 500 mg orally one day, followed by $250 \mathrm{mg}$ orally daily for 4 more days. Ig G titers for $B$. henselae were reduced by half two months later. The patient is currently asymptomatic.

\section{DISCUSSION}

To solve this case we started from a pathological diagnosis, but it was the anamnesis and examination that led us to diagnosis. We acknowledge that the order of action should have been inverse and that a PCR of B. henselae at the sample would have made the diagnosis.

NGL can be produced by various diseases that have been described above [1]. Granulomas are organized aggregates of macrophages and other immune cells that arise as biological structures in response to persistent (infectious or not) stimuli. Although they are defensive complexes, they can also transform into differentiated pathological structures. One of these would be necrosis, produced by macrophages. For reasons not entirely understood yet, some granulomas remain without necrosis (those caused by beryllium, sarcoidosis or Crohn's disease), while others, especially those caused by tuberculosis 
and other infectious diseases (especially intracellular bacteria and fungi) do undergo it [5]. In a Danish study, 121 patients with lymphadenopathy with granulomatous inflammation in the neck and head were analysed. The most frequent diagnoses were sarcoidosis $(26 \%)$, tuberculosis $(22 \%)$, cat scratch disease $(6 \%)$, non-tuberculous mycobacteria $(7 \%)$, tumors $(2 \%)$ and others (4\%), with 33\% of the patients without an established diagnosis. In the case of tuberculosis, the granulomas were normally necrotizing, being non-necrotizing in sarcoidosis [6]. However, a German study found that cat scratch diseases was present in 13.4\% of the 454 patient with head and neck lymphadenopathy analysed, being reticular abscessed granuloma the most frequent pathological finding [7]. Diagnosis in the case of NGL can be challenging because the probability of tuberculosis is remarkable and the detection of bacilli may not be possible with conventional methods due to the low bacillary load in certain extrapulmonary territories, being necessary occasionally to confirm the diagnosis according to the response to anti-tuberculosis treatment $[8,9]$.

Cat scratch disease is an infectious disease caused by $B$. henselae, a Gram-negative bacillus found in cats and fleas. It can be transmitted to humans through bites or scratches. The typical presentation is in children and usually presents with soft, enlarged and sometimes suppurative adenopathy, especially if there has been exposure to cats (mostly kittens, as happened in our case). One or two weeks after the inoculation wound, unilateral regional lymphadenopathies appear, which can persist for months. Other symptoms present may be malaise, arthromyalgia, anorexia, and low-grade fever. Visceral involvement has also been described, mainly hepatosplenomegaly with or without lymphadenopathy, as well as fever of unknown origin in children and occasionally meningoencephalitis, endocarditis and ocular involvement [10]. In immunosuppressed patients, B. henselae can cause bacillary angiomatosis, in which multisystem involvement can occur, especially skin, bone, liver and spleen $[11,12]$.

Regarding epidemiology in Spain, seroprevalence in cats has been found in 29-78\% of samples [13-15]. In humans, some studies have shown differences in seroactivity against $B$. henselae, especially considering the variable titers limit chosen to stablish exposure or infection. We could found serological evidence of $B$. henselae in $8.7-13.55 \%[16,17]$ of healthy people, being higher in occupational jobs like veterinaries (37.1\%) [18].

Diagnosis is serological, because $B$. henselae is difficult to culture. Titers less than 1:64 make the diagnosis unlikely; between 1:64 and 1:256 imply possible infection; greater than 1:256 make it very likely. IgM positivity suggests recent infection. It is important to highlight, as it happened in our case, that cross-reactivity frequently occurs in IgG titers between $B$. henselae and B. quintana. PCR tests can help to achieve diagnosis [10], although in our case the clinical history and the evaluation of the titers of both serologies were conclusive since, although B. quintana can cause trench fever and a similar clinical picture, is associated with the presence of lice and poor hygienic sanitary conditions [19].
Regarding treatment, there have been discrepancies classically in the literature about the use of antibiotics because in many cases cat scratch disease can be self-limited [10] although clinical practice guidelines recommend treatment in patients over $45 \mathrm{~kg}$ with $500 \mathrm{mg}$ of azithromycin the first day followed by $250 \mathrm{mg}$ per day for 4 more days. Patients weighing less than $45 \mathrm{~kg}$ (paediatrics) the dose would be $10 \mathrm{mg} / \mathrm{kg}$ the first day and $5 \mathrm{mg} / \mathrm{kg}$ the four following [20].

\section{FINAL DIAGNOSIS}

Cat scratch disease caused by $B$. henselae.

\section{FUNDING}

None to declare

\section{CONFLICT OF INTERESTS}

Authors declare no conflict of interests

\section{REFERENCES}

1. Asano S. Granulomatous lymphadenitis. J Clin Exp Hematop. 2012;52(1). doi:10.3960/js/rt.52.1

2. Dorfman RF, Berry GJ. Kikuchi's histiocytic necrotizing lymphadenitis: An analysis of 108 cases with emphasis on differential diagnosis. Semin Diagn Pathol. 1988; Nov;5(4):329-45. PMID: 3217625.

3. Kojima M, Motoori T, Asano S, Nakamura S. Histological diversity of reactive and atypical proliferative lymph node lesions in systemic lupus erythematosus patients. Pathol Res Pract. 2007;203(6). doi:10.1016/j.prp.2007.03.002

4. Brouqui $P$, Bacellar F, Baranton G, Birtles RJ, Bjoërsdorff A, Blanco $J R$, et al. Guidelines for the diagnosis of tick-borne bacterial diseases in Europe. Clin Microbiol Infect. 2004;10(12). doi:10.1111/ j.1469-0691.2004.01019.x

5. Pagán AJ, Ramakrishnan L. The Formation and Function of Granulomas. Annu Rev Immunol. 2018;36. doi:10.1146/annurev-immunol-032712-100022

6. Flyger TF, Larsen SR, Kjeldsen AD. Granulomatous inflammation in lymph nodes of the head and neck-a retrospective analysis of causes in a population with very low incidence of tuberculosis. Immunol Res. 2020;68(4). doi:10.1007/s12026-020-09144-6

7. Ridder GJ, Boedeker CC, Technau-Ihling K, Grunow R, Sander A. Role of cat-scratch disease in lymphadenopathy in the head and neck. Clin Infect Dis. 2002;35(6). doi:10.1086/342058

8. Chakravorty S, Sen MK, Tyagi JS. Diagnosis of extrapulmonary tuberculosis by smear, culture, and PCR using universal sample processing technology. J Clin Microbiol. 2005;43(9). doi:10.1128/ JCM.43.9.4357-4362.2005

9. Alves F, Baptista A, Brito $H$, Mendonça I. Necrotising granulomatous lymphadenitis. BMJ Case Rep. Published online 2011. doi:10.1136/bcr.11.2010.3548 
10. Klotz SA, lanas V, Elliott SP. Cat-scratch Disease. Am Fam Physician. 2011. Jan 15;83(2): 152-5. PMID 21243990

11. Zangwill KM. Cat Scratch Disease and Bartonellaceae. Pediatr Infect Dis J. 2021;40(5S). doi:10.1097/inf.0000000000002776

12. Rodríguez Alonso $B$, Alonso-Sardón $M$, Rodrigues Almeida $H M_{1}$ Romero-Alegria Á, Pardo-Lledias J, Velasco-Tirado V, et al. Epidemiological of cat scratch disease among inpatients in the Spanish health system (1997-2015). Eur J Clin Microbiol Infect Dis. 2021 Apr;40(4):849-857. doi: 10.1007/s10096-020-04087-0.

13. Gracia MJ, Marcén JM, Pinal R, Calvete $C$, Rodes D. Prevalence of Rickettsia and Bartonella species in Spanish cats and their fleas. J Vector Ecol. 2015 Dec;40(2):233-9. doi: 10.1111/jvec.12159.

14. Pons I, Sanfeliu I, Quesada M, Anton E, Sampere M, Font B, et al. Prevalence of Bartonella henselae in cats in Catalonia, Spain. Am J Trop Med Hyg. 2005 Apr;72(4):453-7. PMID: 15827285.

15. Álvarez-Fernández $A$, Baxarias $M$, Prandi $D$, Breitschwerdt EB, Solano-Gallego L. Bartonella henselae antibodies in serum and oral fluid specimens from cats. Pathogens. 2021 Mar 11;10(3):329. doi: 10.3390/pathogens10030329.

16. Santibáñez $S$, Caruz A, Márquez-Constán J, Portillo A, Oteo JA, Márquez FJ. Serologic study of Bartonella sp. infection among human population of Southern Spain. Enferm Infecc Microbiol Clin (Engl Ed). 2020 Dec 14:S0213-005X(20)30399-2. doi: 10.1016/j. eimc.2020.10.020.

17. Pons I, Sanfeliu I, Cardeñosa N, Nogueras MM, Font B, Segura F. Serological evidence of Bartonella henselae infection in healthy people in Catalonia, Spain. Epidemiol Infect. 2008 Dec;136(12):1712-6. doi: 10.1017/S0950268808000368.

18. Portillo A, Maggi $R$, Oteo JA, Bradley J, García álvarez L, San martín $M$, et al. Bartonella spp. Prevalence (serology, culture, and PCR) in sanitary workers in La Rioja Spain. Pathogens. 2020 Mar 4;9(3):189. doi: 10.3390/pathogens9030189.

19. Foucault C, Brouqui P, Raoult D. Bartonella quintana characteristics and clinical management. Emerg Infect Dis. 2006;12(2). doi:10.3201/eid1202.050874

20. Stevens DL, Bisno AL, Chambers HF, Dellinger EP, Goldstein EJC, Gorbach SL, et al. Practice guidelines for the diagnosis and management of skin and soft tissue infections: 2014 update by the infectious diseases society of America. Clin Infect Dis. 2014;59(2). doi:10.1093/cid/ciu296 